\title{
Role of lidocaine (lignocaine) in managing status epilepticus
}

\author{
Julio Pascual, Jesús Ciudad, José Berciano
}

\begin{abstract}
Lidocaine (lignocaine) was given in 42 episodes of status epilepticus (SE) in 36 patients either because of limited pulmonary reserve (22 patients) or because of lack of response to diazepam (14 patients). Lidocaine (1.5-2 $\mathrm{mg} / \mathrm{kg})$ was given intravenously in two minutes. A further identical bolus was infused if no response had occurred or if seizures recurred. With the first bolus 11 episodes of SE did not stop, but 31 responded, always in less than one minute. In 19 episodes, however, this response lasted less than 30 minutes. Twelve episodes did not recur, but 30 needed a second bolus because of recurrence. Of these, 19 episodes responded at once but SE reappeared in seven. In these seven episodes the mean control time with the second dose was 102 minutes. Five of these subsequently responded to a continuous infusion of lidocaine. Eleven patients, who had not responded to the first bolus, had no response to the second. Lidocaine is a drug that may be epileptogenic at high doses. At the doses used here, however, lidocaine seems to be a rapid acting anticonvulsant, useful in the short term management of SE and may be indicated in patients in whom respiratory or consciousness depression is undesirable and in those with no response to diazepam. The absence of response to lidocaine indicates SE resistant to treatment and poor prognosis. These data show that prompt lidocaine administration may be worthwhile when management of respiratory depression is not possible.
\end{abstract}

Unfortunately there is still no ideal drug for treating status epilepticus (SE). ${ }^{1}$ High dose phenytoin or phenobarbital are currently the initial treatment of choice, ${ }^{12}$ but the action of both drugs is far from prompt. Phenytoin solution takes several minutes, and if iv phenytoin is given at the maximum rate of $50 \mathrm{mg} / \mathrm{min}$ it will take about 20 minutes to administer a full loading dose. Thus the action of phenytoin may be evident only after at least 30-50 minutes from starting the infusion. ${ }^{134}$ Therefore, a rapid acting anticonvulsant is needed to control seizures while a phenytoin solution is prepared and begins to exert its beneficial effects. Several benzodiazepines, mainly diazepam and lately lorazepam, have been widely used for this purpose. ${ }^{56}$ Diazepam and phenytoin stop up to $95 \%$ of primarily generalised $\mathrm{SE}$, but they control only $65 \%$ of partial onset SE. ${ }^{13}$ Thus a significant number of patients will need iv phenobarbitone or general barbiturate anaesthesia. This requires endotracheal intubation and mechanical ventilation. ${ }^{1}$ Ventilatory complications may occur in older patients and in people with previous limited pulmonary reserve, especially if diazepam has been administered before phenobarbitone. ${ }^{57}$ Theoretically, lidocaine, a drug devoid of significant depressing effects on consciousness and the respiratory centre, ${ }^{7}$ may be safer in these patients. Since 1955 this drug has been used with success as an anticonvulsant, according to scattered reports in patients with $S E .^{7-14}$ The actual role of lidocaine in the management of SE, however, is not clear; we do not know either its ideal antiepileptic dose or the temporal profile of its action. Recently, in a preliminary study of eight cases, we found that lidocaine may be used safely in patients in whom respiratory depression would be dangerous and in SE with no response to iv diazepam. ${ }^{14}$ We present a prospective series of patients in SE in whom lidocaine was used because of absence of response to adequate doses of diazepam or as the first choice drug because of limited pulmonary reserve.

\section{Patients and methods}

Definition and general management of SE was performed by an experienced neurologist as previously stated. $^{12}$ In summary, after inserting an oral airway and administering oxygen, cardiorespiratory monitoring was carried out. Subsequently, an iv infusion with normal saline was started, thiamine and glucose also being administered. ${ }^{12}$ If after 10 minutes seizures persisted iv diazepam was infused at a rate no faster than $2 \mathrm{mg} / \mathrm{min}$, until seizures stopped, or to a maximum of $20 \mathrm{mg}$. All patients also received sodium phenytoin. This drug was given iv no faster than $50 \mathrm{mg} / \mathrm{min}$ to a total dose of $18 \mathrm{mg} / \mathrm{kg}$. Lidocaine was used instead of diazepam in patients with limited pulmonary reserve and in those who had not responded to iv diazepam. All patients considered as having limited pulmonary reserve had a history of excessive tracheobronchial mucus production and cough with expectoration for more than three months of the year for at least the last three years and a history of dyspnoea and impairment of physical work capacity.${ }^{15}$ In addition, chest $\mathrm{X}$ ray pictures and blood gases showed in every case chronic 
Table 1 Results of treatment with lidocaine

\begin{tabular}{|c|c|c|c|c|c|}
\hline & \multirow[b]{3}{*}{ Number } & \multirow[b]{3}{*}{ Onset } & \multicolumn{3}{|l|}{ Duration } \\
\hline & & & \multicolumn{2}{|c|}{ Recurrence } & \multirow[b]{2}{*}{ No recurrence } \\
\hline & & & $<30 \min$ & $>30 \min$ & \\
\hline \multicolumn{6}{|c|}{ First bolus (usually $100 \mathrm{mg}, 42$ episodes of $S E$ ) } \\
\hline $\begin{array}{l}\text { Response } \\
\text { No response }\end{array}$ & $\begin{array}{l}31 \\
11\end{array}$ & Always $<1 \mathrm{~min}$ & 18 & 1 & 12 \\
\hline \multicolumn{6}{|c|}{ Second bolus (usually $100 \mathrm{mg}$, in 30 episodes of $S E$ ) } \\
\hline $\begin{array}{l}\text { Response } \\
\text { No response }\end{array}$ & $\begin{array}{l}19 \\
11^{\star}\end{array}$ & Always $<1 \mathrm{~min}$ & 1 & 6 & 12 \\
\hline \multicolumn{6}{|c|}{ Continuous infusion (3-4 mg/kg in 8 episodes of $S E$ ) } \\
\hline $\begin{array}{l}\text { Response } \\
\text { Total } \\
\text { Partial } \\
\text { No response }\end{array}$ & $\begin{array}{l}5 \\
3 \\
2 \\
3\end{array}$ & & & & \\
\hline
\end{tabular}

« Same SE that did not respond to first dose.

restrictive or obstructive lung disease. ${ }^{15}$ Functional studies performed in 16 out of the 22 patients with history of chronic obstructive lung disease showed that $\mathrm{FEV}_{1}$ fell below $50 \%$ of that predicted. Lidocaine, $1.5-2 \mathrm{mg} / \mathrm{kg}$ (usually $100 \mathrm{mg}$ ), was administered as a single iv dose in 2 minutes. A further identical dose was given if no positive response had occurred or, if after stopping, seizures recurred. In these two boluses no patient received more than 200 $\mathrm{mg}$. A lidocaine continuous infusion at a rate of 3-4 $\mathrm{mg} / \mathrm{kg} / \mathrm{hour}$ was started only if after the initial control with lidocaine seizures recurred. Patients with known or suspected cardiopathy were excluded from this study.

\section{Results}

Thirty six patients were included in this study. They had suffered a total of 42 episodes of SE: seven partial episodes, 22 secondarily generalised episodes, and seven primarily generalised episodes. There were 12 women and 24 men, aged between 16 and 89 years. The aetiologies were varied; SE secondary to cerebrovascular disease in 23 patients being the most common diagnosis. Lidocaine was given to 22 patients because of chronic restrictive or obstructive lung disease and in 14 cases because of no response to previous diazepam administration.

First dose (table 1)

Eleven episodes did not respond to the first dose; 31 did respond. In the patients who responded the convulsions ceased immediately, always in less than one minute after administration. In 19 episodes, however, this response was short, convulsions reappearing between three and 30 minutes later in 18 and after two hours in one episode.

Table 2 Comparison between episodes of $S E$ with and without response

\begin{tabular}{lll}
\hline & Non-responders & Responders \\
\hline Number of episodes & $11(26 \%)$ & $31(74 \%)$ \\
Number of patients & $11(30 \cdot 5 \%)$ & $25(69 \cdot 5 \%)$ \\
Type of SE & & \\
Partial onset & $10(91 \%)$ & $19(76 \%)$ \\
$\quad$ Primarily generalised & $1(9 \%)$ & $6(24 \%)$ \\
Primary aetiology & $7(64 \%)$ & $16(64 \%)$ \\
$\quad$ Vascular & $2(18 \%)$ & 0 \\
Metabolic & $2(18 \%)$ & $9(36 \%)$ \\
Others & 4 & 0 \\
Serious systemic disease & 4 & 1 \\
Deaths & & \\
\hline
\end{tabular}

Second dose (table 1)

Twelve episodes of SE did not receive the second bolus of lidocaine because there was no recurrence of seizures. Thirty episodes needed a second bolus either because of no response to the first bolus ( 11 episodes) or because of the reappearance of convulsions after an initial control (19 episodes). Nineteen episodes again responded at once, in 12 the episode not recurring. In the remaining seven convulsions reappeared in 10 minutes to three hours. Only in one of these seven was this response short ( 10 minutes), the mean time of control with this dose in these seven cases being 102 minutes. Eleven episodes did not respond to the second dose. Interestingly, these latter patients were the same as those with previous absence of response to the first dose. We analysed the group of 11 patients with no response to lidocaine (table 2). The aetiologies were seven cases secondary to vascular disease $(64 \% v$ $64 \%$ in the responders), one glioma, one case of static encephalopathy, and the two cases of metabolic SE seen in this series. Ten episodes were of partial onset $(91 \% v 76 \%$ in the responders). In this particular group without response, three subsequently responded to diazepam but eight episodes did not respond to diazepam and phenobarbitone or phenytoin or both, thus needing barbiturate anaesthesia.

\section{Continuous infusion}

Continuous lidocaine infusion, $3.5 \mathrm{mg} / \mathrm{kg} /$ hour, was administered in the seven episodes that reappeared after responding to the second bolus. In two no positive effect was obtained, while five episodes showed a positive response. Of these, three exhibited a complete, infusiondependent response, convulsions reappearing 15 to 30 minutes after the infusion was stopped and ceasing again with the infusion. In the other two the response was clear, with at least $50 \%$ reduction in the frequency and intensity of convulsions, but not complete. Of the group of patients with no response to the boluses, only one received iv infusion with no positive effects.

No significant undesirable effects were observed. We saw slight hypotension after lidocaine administration in only two cases, which subsided with normal saline. There were five deaths in our series. Only one patient of the group with response to lidocaine died. This was an 87 year old man with severe chronic obstructive lung disease and prolonged convulsions (for 10 hours) before lidocaine, in whom cardiopulmonary arrest ensued after successful control of the episode for six hours with lidocaine only. This patient had had no response to diazepam and phenytoin before being transferred to our centre. The remaining four deaths took place in the group with no response to lidocaine and were clearly related to their underlying diseases (leukaemia, cirrhosis, disseminated breast cancer, and serious coagulopathy).

\section{Discussion}

Our data, showing a positive response to lidocaine in $74 \%$ of the episodes of SE, 
demonstrate that lidocaine may be effective in the prompt treatment of SE in patients with limited pulmonary reserve, avoiding the sedation and respiratory compromise of benzodiazepines. Also lidocaine administration seems to be worthwhile in some patients with no initial response to the standard diazepam/ phenytoin combination, providing time to check the phenytoin concentrations or to infuse new anticonvulsants such as phenobarbitone. This may finally avoid the necessity of anaesthesia or delay it allowing us time, for instance, to transfer the patients to an intensive care unit.

Neither the ideal dosage nor the temporal profile of this drug have been stated in previous studies. With the initial dose used (about 1.5-2 $\mathrm{mg} / \mathrm{kg}$ body weight) $74 \%$ of episodes of SE were controlled. Although prompt, this response was habitually short; 19 episodes recurred, in 18 the response being shorter than 30 minutes. The prolonged response to this first bolus of lidocaine observed in the remaining 12 episodes is probably better explained by the phenytoin. Though we did not study the pharmacokinetics of lidocaine in our patients it is well known that after an iv bolus lidocaine is initially distributed to a few highly perfused tissues (heart, brain, kidneys, liver). ${ }^{16}$ This allows for the rapid achievement of therapeutic lidocaine concentrations by a dose smaller than that necessary to produce comparable concentrations after complete distribution. Early plasma concentrations, however, decrease rapidly because of the redistribution to peripheral tissues. Therefore, the half life of this initial bolus is in the range of four to eight minutes, ${ }^{16}$ thus explaining the results with the first bolus.

In contrast with the usual brief action seen with the first dose, 19 episodes had a more prolonged response to the second dose. Although this long response could be explained by the action of the phenytoin, our data do not support that. The response to this second bolus was again immediate (<one minute), and in the 18 episodes with short initial response to the first bolus, lidocaine alone seemed to control the SE for at least 30-50 minutes because in these cases the second lidocaine bolus was administered at the same time or even before phenytoin due to the time taken to prepare the phenytoin infusion. Also, phenytoin concentration was not enough to control the seven episodes of SE that recurred at a mean of 102 minutes after the second bolus. Interestingly, this time coincides with the expected half life of this second bolus, which is usually in the range of 70-130 minutes. ${ }^{1316}$ Moreover, these seven episodes were treated with continuous infusion to which five of them responded. This confirms again the anticonvulsant actions of lidocaine in SE. Therefore, the profile of lidocaine action in SE is similar to that of diazepam. From these data it seems clear that lidocaine is a rapid acting anticonvulsant and that doses of $3 \mathrm{mg} / \mathrm{kg}$ are usually necessary to control the SE until the antiepileptic actions of phenytoin or phenobarbital appear. In the eight cases in which continuous infusion was employed the SE was completely controlled in only three, perhaps because of the relatively low dose administered in comparison with the recommendations of others. ${ }^{813}$ Lidocaine may have proconvulsant effects but these symptoms are dose-dependent, usually appearing when more than $300 \mathrm{mg} /$ hour have been infused, leading to plasma drug concentrations over $6 \mathrm{mg} / 1 .^{16}$ Thus, pending new experience, it seems reasonable not to exceed the maximum recommended dosage $(200-300 \mathrm{mg} /$ hour$){ }^{7}$ Eleven episodes did not respond either to the boluses or to the continuous infusion. In our experience, as Browne suggested, ${ }^{7}$ episodes of SE that do not stop with $100 \mathrm{mg}$ of lidocaine probably will not respond to subsequent doses of this drug. The absence of response to lidocaine is usually indicative of SE resistant to treatment and poor prognosis and is more commonly seen in patients with serious systemic disorders and in SE with partial onset.

In conclusion, lidocaine, like diazepam, is a rapid-acting anticonvulsant which is useful in short term management of the SE and may be indicated as a first line drug in patients in whom respiratory or consciousness depression is undesirable or as a second line drug in those episodes of SE that do not respond to diazepam. Our data suggest that, as in the treatment of ventricular arrythmias induced by myocardial infarction, prompt lidocaine administration for SE may be worthwhile particularly when patients are being transferred and management of respiratory depression is not possible.

We thank John Hawkins for revising the manuscript and the members of our Neurology Service for their help in managing the patients.

1 Delgado-Escueta AV, Treiman DM. The emergency treatment of status epilepticus. In: Johnson KT, ed Current therapy in neurologic disease. Philadelphia: B C Decker Inc 1985:51-60.

2 Delgado-Escueta AV, Wasterlain C, Treiman DM, Porter RJ. Management of status epilepticus. N Engl J Med 1982;306:1337-40.

3 Delgado-Escueta AV, Enrile-Bacsal F. Combination therapy for status epilepticus: intravenous diazepam and phenytoin. In: Delgado-Escueta AV, Wasterlain CG Treiman DM, Porter RJ, eds. Status epilepticus: mechanisms of brain damage and treatment. Advances in neurology. New York: Raven Press, 1983;34:477-86.

4 Leppik IE, Patrick BK, Cranford RE. Treatment of acute seizures and status epilepticus with intravenous phenytoin. In: Delgado-Escueta AV Wasterlain CG Treiman DM, Porter RJ, eds. Status epilepticus: mechanisms of brain damage and treatment. Advances in neurology. New York: Raven Press, 1983;34:447-52.

5 Tassinari CD, Daniele $O$, Michelucci $R$, et al. Benzodiazepines: efficacy in status epilepticus. In: Delgado-Escueta AV, Wasterlain CG, Treiman DM Porter RJ, eds. Status epilepticus: mechanisms of brain Porter RJ, eds. Status epilepticus: mechanisms of brain damage and treatment. Advances

6 Leppik IE, Derivan AT, Homan RW, Walker J, Ramsay RE, Patrick B. Double-blind study of lorazepam and diazepam in status epilepticus. JAMA 1983;249:1452-4.

7 Browne TR. Status epilepticus. In: Browne RT, Feldman RG, eds. Epilepsy: diagnosis and management. Boston: Little Brown, 1983:341-54.

8 Bernhard CG, Bohm E, Höjeberg S. A new treatment of status epilepticus, intravenous injections of a local anaes-
thetic (lidocaine). Arch Neurol Psychiatr1955;74:208-14.

9 Taverner D, Bain WA. Intravenous lidocaine as an anticonvulsant: in status epilepticus and serial epilepsy. convulsant: in status
Lancet 1958;ii:1145-57.

10 Westreich G, Kneller W. Intravenous lidocaine for status epilepticus. Min Med 1972;55:807-9.

11 Lemmen LJ, Klassen M, Druiser B. Intravenous lidocaine in the treatment of convulsions. JAMA 1978;239:2025.

12 Tsukamoto $S$, Horiike N, Hisanaga $M$, Utsumi $S$. The efficacy of lidocaine in status epilepticus. Brain Nerve 1980;32:363-8.

3 Hellström-Westas L, Westgren U, Rosén I, Svenningsen NW. Lidocaine for treatment of severe seizures in newborn infants. Acta Paediatr Scand 1988;77:79-84.

14 Pascual J, Sedano MJ, Polo JM, Berciano J. Intravenous lidocaine for status epilepticus. Epilepsia 1988;29:584-9.

5 Ingram RHJr. Chronic bronchitis, emphysema, and airways obstruction. In: Wilson JD, Braunwald E, Isselbacher KJ, et al eds. Harrison's principles of internal medicine. New York: McGraw-Hill, 1991:1074-82.

16 Nattel S, Gagne G, Pineau M. The pharmacokinetics of lignocaine and $\beta$-adrenoceptor antagonists in patients with acute myocardial infarction. Clin Pharmacok 1987;13:293-316. 